\title{
MEDIA PEMBELAJARAN INTERAKTIF UNTUK MENGENAL ANGGOTA TUBUH SAPI DAN BANGUN DATAR PADA KELOMPOK BERMAIN AL-ISTIGHFAR
}

\author{
Retno Wahyusari ${ }^{1 *}$, Adhika Pramita Widyassari ${ }^{1}$, Ratna Dwi Rahayu ${ }^{\mathbf{1}}$ \\ ${ }^{1}$ Sekolah Tinggi Teknologi Ronggolawe, Cepu, Indonesia \\ *retnowahyusari@gmail.com
}

\begin{abstract}
Abstrak: Kegiatan belajar mengajar pada kelompok bermain (KB) Al- Istighfar masih terkendala pada terbatasnya penggunaan media pembelajaran interaktif dalam proses pembelajaran. Proses pembelajaran hanya menggunakan gambar poster, papan tulis dan beberapa peraga sederhana. Tujuan pelaksanaan kegiatan pengabdian adalah pengembangan media pembelajaran interaktif yang mampu memberikan alternatif dalam penyampaian materi agar siswa tidak mengalami kebosanan dalam belajar serta meningkatkan minat untuk belajar. Metode yang digunakan dalam pengabdian masyarakat ini adalah pelatihan dan pendampingan dengan tiga tahapan kegiatan. Tahap pertama adalah penentuan konsep dan rancangan desain media melalui kegiatan diskusi dan wawancara dengan guru sebagai mitra. Tahap kedua adalah pengumpulan materi dan pembuatan media pembelajaran oleh tim pengabdian. Tahap ketiga adalah uji coba media, pengaplikasian media pada proses pembelajaran, pelatihan penggunaan media kepada guru, dan penyerahan produk media pembelajaran kepada guru sebagai mitra kegiatan. Evaluasi dampak pengabdian ini diukur dengan menggunakan kuesioner untuk melihat tanggapan guru terhadap produk media pembelajaran yang selanjutnya dianalisis dengan menggunakan skala Likert. Persentase rata-rata hasil kuesioner adalah sebesar $88 \%$ yang menunjukkan pengembangan media pembelajaran interaktif masuk pada kategori yang baik. Dapat disimpulkan bahwa media pembelajaran interaktif yang dikembangkan dalam program pengabdian ini dapat menjadi alternatif bagi guru dalam penyampaian materi pembelajaran untuk meningkatkan respon, minat belajar, dan fokus anak sehingga siswa tidak mengalami kebosanan dalam belajar.
\end{abstract}

Kata Kunci: media interaktif, pembelajaran, kelompok bermain

\begin{abstract}
Teaching and learning activities in the Al-Istighfar play group are still constrained by the limited use of interactive learning media. The learning process only uses posters, blackboards, and some simple demonstrations. The purpose of this community service program is to develope an interactive learning media that is able to provide alternatives in delivering material so that students do not experience boredom and increase interest to the learning as well. The method used in this community service is training and mentoring in three stages. The first stage was determining the concept and design of media designs through discussions and interviews with the teachers as partners. The second stage was collecting the materials and creating the learning media by the team of community service program. The third stage was testing the media, implementing media in the learning process, training the teachers, and delivering the learning media products to teachers as the community service partners. The evaluation of this program was measured through a questionnaire to examine the teachers' responses to learning media products which were then analyzed using a Likert scale. The average percentage of questionnaire results is $88 \%$, which shows that the development of interactive learning media is in the good category. It can be concluded that the interactive learning media developed in this service program can be an alternative for teachers in delivering learning materials to increase students' responses, interest in learning, and focus so that students do not get bored in learning.
\end{abstract}

Keywords: interactive media, learning, play group

\section{Pendahuluan}

Anak usia dini berada pada masa keemasan dalam perkembangan pendidikan, maka diperlukan pendidikan anak usia dini. Pendidikan anak usia dini berpengaruh terhadap kemampuan dan ketrampilan anak. Dimana nantinya berperan penting dalam pengembangan 
kepribadian anak, serta mempersiapan anak memasuki pendidikan selanjutnya (Tatik Ariyanti, 2016; Febiola, 2020 \& Ayuni, 2019). Kegiatan pembelajaran pada pendidikan anak usia dini kebanyakan berupa permainan. Pengalaman bermain yang menyenangkan dapat membantu perkembangan anak secara optimal (Ayuni, 2019). Kegiatan bermain memerlukan media yang digunakan dalam menyampaikan suatu materi. Media yang digunakan dalam menyampaikan materi disebut sebagai media pembelajaran. Media pembelajaran memiliki peranan yang sangat penting dalam mencapai pembelajaran yang efektif (Mardhiah \& Ali Akbar, 2018; Tafonao, 2018; Nurrita, 2018 \& Lesmana, et al., 2018). Media pembelajaran dapat mengalihkan perhatian anak agar mereka tidak cepat mengalami kebosanan (Yanti, Anggraini \& Darwanto, 2019).

Meskipun media pembelajaran sangat penting, tetapi pemanfaatan dan penerapan media pembelajaran merupakan salah satu problematika dalam pendidikan dan pembelajaran pada PAUD, TK/ RA di Indonesia (Anam, 2021). Salah satu upaya dalam mengatasi problematika tersebut adalah dengan kegiatan pengembangan media pembelajaran. Bentuk perkembangan media pembelajaran adalah media pembelajaran interaktif. Media pembelajaran interaktif adalah media pembelajaran yang menggabungkan berbagai media (gambar, suara, grafik, dan lain-lain) dan memanfaatkan teknologi didalamnya (Shalikhah, 2017).

Kendala pemanfaat dan pengembanagan media pembelajaran juga dialami oleh KB AlIstighfar. Hasil wawancara dengan kepala sekolah KB Al-Istighfar menunjukkan bahwa proses kegiatan belajar mengajar masih terkendala pada keterbatasan media pembelajaran interaktif yang dimiliki. Saat ini proses pembelajaran hanya menggunakan gambar poster, papan tulis dan beberapa peraga sederhana. Media pembelajaran yang dimiliki saat ini kurang dapat menarik perhatian siswa dan kurang efektif dalam penyampaian materi. Melihat kondisi tersebut maka kegiatan pengabdian membuat mengembangkan media pembelajaran interaktif.

Beberapa penelitian terdahulu telah mengembangkan media pembelajaran interaktif untuk mendukung proses pembelajaran. Wicaksono \& Qhadafhi (2019) membuat media pembelajaran untuk mengenal bentuk bangun geometri memanfaatkan mikrokontroler. Media pembelajaran mampu mendeteksi benda geometri yang diletakkan pada media, hasilnya dikeluarkan dengan suara dan layar LCD. Pada media pembelajaran ini siswa menekan tombol jika benda geometri telah siap untuk dideteksi sensor. Tujuan dari pengembangan media pembelajaran ini adalah media pembelajaran interkatif yang dapat menarik minat anak usia dini untuk belajar mengenali dan mengingat pola geometri. Hasil media pembelajaran berhasil mengenali benda geometri sebesar $100 \%$.

Penelitian terkait pengembangan media pembelajaran yang lain juga dilakukan oleh Nusyirwan \& Purnama (2019) menggunakan mikrokontroler dan kartu RFID dalam pembuatan media pada materi berisi tentang tebak pilihan ikan dengan bentuk permainan ular tangga. Tujuannya adalah menebak dan mengenal jenis ikan, memberikan kontribusi pada ketahanan wilayah terpencil serta mengedukasi anak sekolah dasar terhadap teknologi dengan menumbuhkan rasa keingin tahuan terhadap potensi wilayah.

Jufriyanto, et al. (2020) mengembangkan media pembelajaran interaktif berupa pernyortiran barang benda berbasis mikrokontroler. Media pembelajaran memanfaatkan sensor ultrasonik mendeteksi jarak, sensor warna mendeteksi warna, dan sensor proximitymendeteksi 
jenis material dari suatu benda yang akan tersortir, sedangkan sensor infrared (inframerah) berfungsi untuk menghitung jumlah benda yang jatuh ke konveyor. Hasil media pembelajaran yaitu benda akan tersortir berdasarkan perintah yang dimasukkan pada program.

Ketiga pengembangan media pembelajaran interaktif semua menggunakan mikrokontroler, hal ini membuktikan bahwa mikrokontroler dapat digunakan dengan baik untuk pengembangan media pembelajaran interaktif. Penelitian yang dilakukan oleh Bagye, Azizah \& Zulkarnaen (2018) serta Hanggara \& Putra (2021) menyatakan bahwa mikrokontroler mampu mengirimkan/ pembaca data yang baik. Pengembangan media pembelajaran interaktif diatas belum memanfaatkan kapasitif sensor, dimana kapasistif sensor sebagai inputan. Kapasitif sensor merupakan sensor inputan yang lebih mudah digunakan dibandingkan dengan menggunakan sensor tekanan FSR dan piezzo (Yuniaratri, Suryanto \& Mulwinda 2017; Wahyusari, 2018). Pada pengabdian ini pengembangan media pembelajaran interaktif menggunakan mikrokontroler dan kapasitif sensor.

Kegiatan pengabdian ini bertujuan untuk membatu guru dalam menyedikan media pembelajaran interkatif sebagai alternatif dalam menyampaikan materi, meningkatkan minat belajar siswa serta mampu mengalihkan perhatian anak agar tidak bosan. Media pembelajaran interaktif yang dikembangkan berisikan materi hasil wawancara dengan guru sesuai dengan kebutuhan KB Al- Istighfar. Materi yang digunakan dalam media pembelajaran interaktif adalah pengenalan anggota tubuh sapi dan bangun datar. Media pembelajaran interaktif dibuat dengan menggunakan mikrokontroler dan sensor tekan kapasitif sensor. Media pembelajaran interaktif menghasilkan respon audio berdasarkan masukkan dari sensor tekan. Pemberian suara memiliki tujuan agar siswa tertarik dan tidak mudah bosan terhadap materi yang diberikan. Pada materi bangun datar, tidak hanya berisi nama bangun datar tapi juga berisi pengenalan warna. Hal ini bertujuan agar pembelajaran lebih efektif. Selain itu materi mengenal bangun datar berserta mengenal warna, merupakan bagian dari peningkatan kemampuan kognitif dalam lingkup pemikiran logis (Dwansi et al., 2017).

\section{Metode}

Metode pelaksanaan kegiatan pengabdian termasuk dalam pendekatan deskriptif, dimana kegiatan dilaksanakan guna memecahkan sekaligus menjawab permasalahan yang terjadi sekarang (Lesmana et al., 2018). Kegiatan pengabdian dilaksanakan dalam tiga tahapan setiap tahapan memerlukan peran aktif mitra, agar media pembelajaran sesuai dengan kebutuhan mitra. Peran mitra/guru pada tahap pertama adalah memberikan masukkan tentang materi yang akan dibuat dilaksanakan tanggal 2 Maret 2021 membahas kebutuhan guru dan gambaran media yang diinginkan. Tahap kedua adalah kegiatan pengumpulan materi berupa pencarian gambar dan pengumpulan audio, pembuatan media pembelajaran dilaksanakan oleh tim pengabdian. Tahap ketiga adalah uji coba dan pelatihan penggunaan dilaksanakan 16 Maret 2021 yang dilakukan oleh tim pengabdi dan guru. Uji coba aplikasi bertujuan untuk mencari kelemahan atau kesalahan media pembelajaran, sebelum media pembelajaran diserahkan kepada mitra. Penyerahan media pembelajaran dilaksanakan tanggal 17 Maret 2021. Tahap pelaksanaan terlihat pada Gambar 1. 


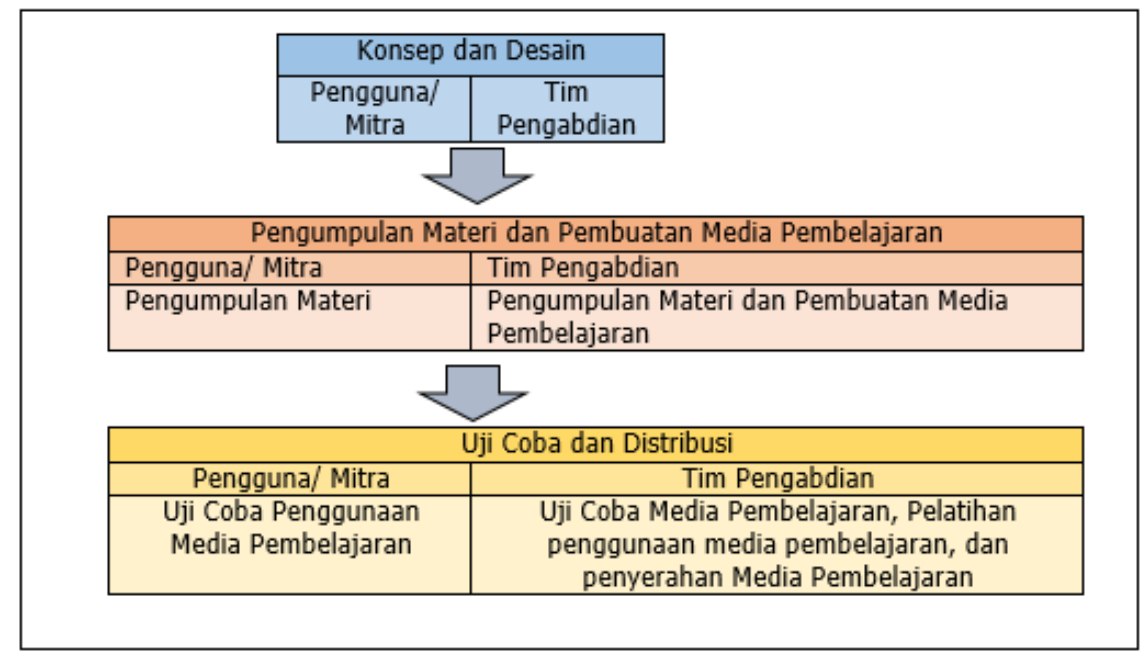

Gambar 1. Tahap Pelaksanaan Program Pengabdian

Setelah semua tahap pengabdian dilaksanakan dan media pembelajaran sudah dimanfaatkan, tim pengabdian memberikan kuesioner kepada guru. Kuesioner terdiri dari 5 (lima) pertanyaan sebagaimana Tabel 1 dan hasilnya diolah menggunakan metode skala Likert.

Tabel 1. Daftar Pertanyaan Kuesioner

\begin{tabular}{l}
\hline \multicolumn{1}{c}{ Butir Pertanyaan } \\
\hline Media pembelajaran membantu saya dalam menyampaikan materi \\
Media pembelajaran memberikan alternatif dalam mengalihkan perhatian anak untuk \\
tidak cepat bosan atau mampu konsentrasi dalam suatu kegiatan dengan waktu yang \\
cukup lama \\
Media pembelajaran dengan respon audio meningkatkan minat belajar siswa \\
Media pembelajaran mudah pengaplikasiannya \\
Media pembelajaran bekerja dengan baik
\end{tabular}

\section{Hasil dan Pembahasan}

Kegiatan pengabdian dilaksanakan di KB. Al-Istighfar Desa Tambakwatu. Tahapan kegiatan pengabdian pengembangan media pembelajaran interaktif sebagai berikut:

1. Konsep dan Desain

Menentukan konsep dan desain dilaksanakan melalui wawancara dengan mitra. Hasil wawancara dengan guru sekolah/mitra dibuat desain media pembelajaran. Materi yang diajukan oleh mitra adalah bagian-bagian dari anggota tubuh sapi (mata, hidung, tanduk, mulut, perut, kaki, ekor) dan bentuk bangun datar (persegi panjang, oval, belah ketupat, trapesium, lingkaran, segi tiga, bujur sangkar). Tim pengabdi mengajukan konsep media pembelajaran yang dibuat menggunakan sensor kapasitif, dimana saat sensor mendapat rangsangan atau tekanan dari luar akan menghasilkan respon audio. Gambar 2 merupakan desain media pembelajaran yang diusulkan. Siswa menyentuh area sensor pada media pembelajaran, maka media pembelajaran akan memberikan respon berupa audio sesuai dengan materi yang sensornya disentuh oleh siswa. Misal siswa menyentuh sensor yang ada pada bangun datar segitiga, maka respon suara yang dihasilkan adalah segitiga berwarna hijau. 


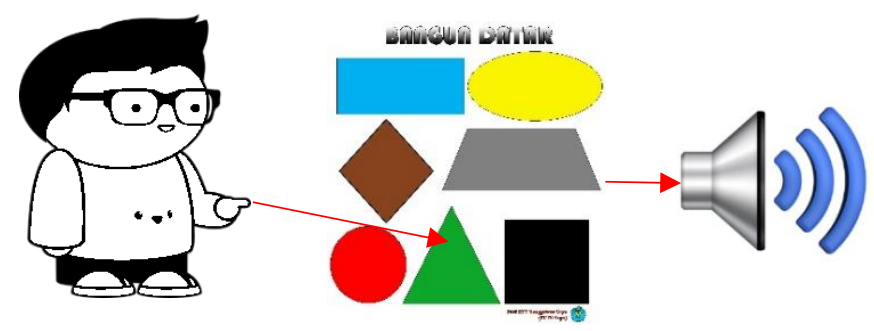

Gambar 2. Desain Media Pembelajaran

2. Pengumpulan Materi dan Pembuatan Media Pembelajaran

Semua kegiatan tahap ini dilaksanakan oleh tim pengabdian di workshop. Materi gambar sapi dan bangun datar didapat melalui internet. Materi audio diambil dengan menggunakan aplikasi online yang merubah teks kedalam suara. Materi yang didapat kemudian disimpan pada kartu memori. Langkah selanjutnya membuat rangkaian media pembelajaran interaktif. Detail rangkaian media pembelajaran interaktif terlihat pada Gambar 3. Modul untuk memainkan materi tersimpan pada kartu memori menggunakan Audio Shield. Sedangkan program untuk membaca masukan dan merubah kedalam keluaran menggunakan Arduino, yang mana program arduino merupakan program open source. Respon audio dikeluarkan melalui speaker. Gambar 4 merupakan hasil dari pengembangan media pembelajaran interaktif, tampak depan dan tampak belakang.

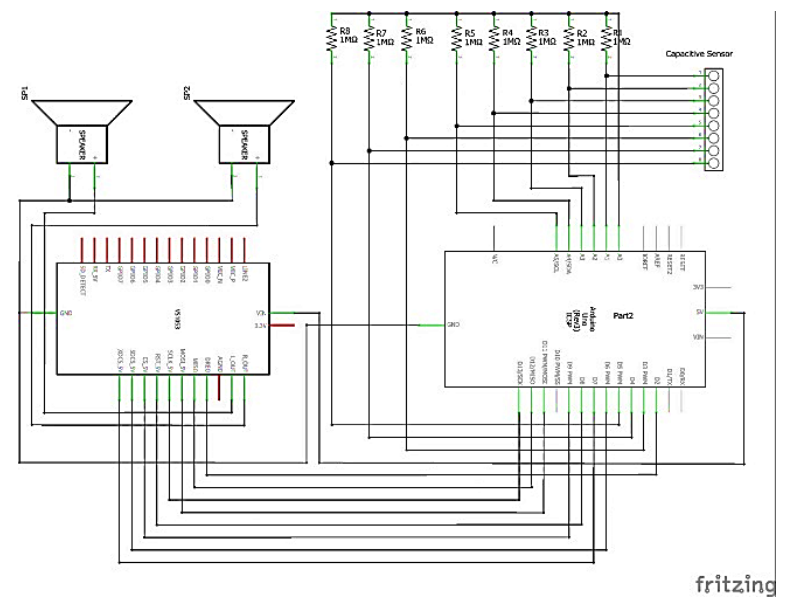

Gambar 3. Rangkaian Media Pembelajaran

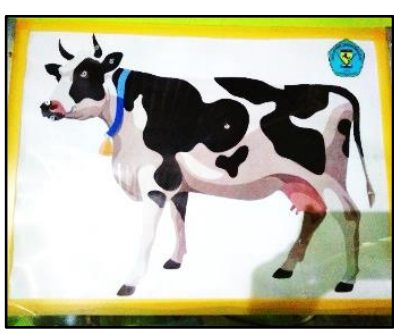

(a)

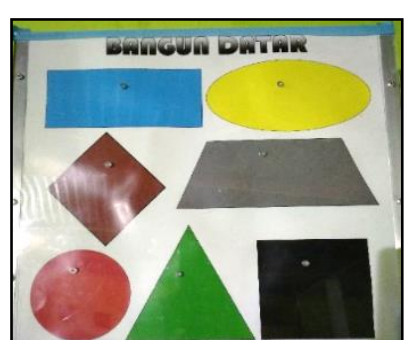

(b)

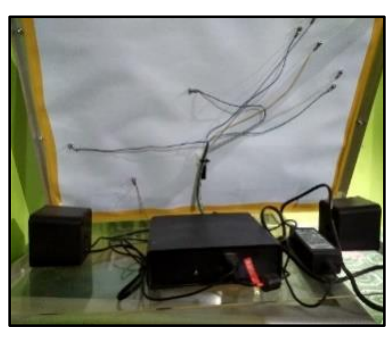

(c)

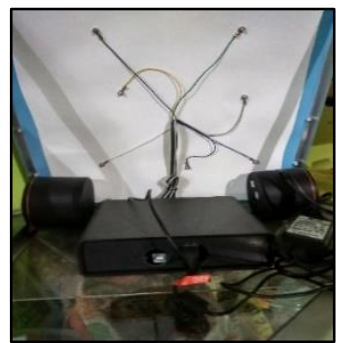

(d)

Gambar 4. (a) dan (b) Tampilan Depan Media Pembelajaran, (c) dan (d) Tampilan Belakang Media Pembelajaran 
3. Uji Coba dan Penyerahan Media Pembelajaran

Uji coba dilaksanakan di workshop Teknik Elektro dan KB. Al-Istighfar. Metode pengujian menggunakan metode black box. Hasil pengujian black box menunjukkan bahwa semua sensor pada kedua media pembelajaran interaktif dapat berfungsi dengan baik. Rangkuman hasil pengujian terlihat pada Tabel 1 dan Tabel 2.

Tabel 2. Pengujian Alat Media Pengenalan Bagian Tubuh Sapi

\begin{tabular}{|c|c|c|c|c|}
\hline No & $\begin{array}{c}\text { Aktifitas } \\
\text { Pengujian } \\
\end{array}$ & $\begin{array}{c}\text { Realisasi yang } \\
\text { diharapkan }\end{array}$ & Hasil pengujian & Kesimpulan \\
\hline 1 & $\begin{array}{l}\text { Tekan sensor bagian } \\
\text { tubuh sapi }\end{array}$ & $\begin{array}{l}\text { Sensor berfungsi } \\
\text { semua yaitu ada } 7 \\
\text { titik }\end{array}$ & $\begin{array}{l}\text { Sensor berfungsi } \\
\text { semua yaitu } \\
\text { sebanyak } 7 \text { titik }\end{array}$ & $\begin{array}{l}\text { [x ] diterima } \\
{[\text { ] ditolak }}\end{array}$ \\
\hline 2 & $\begin{array}{l}\text { Respon audio bagian } \\
\text { tubuh sapi terdengar } \\
\text { saat sensor ditekan }\end{array}$ & $\begin{array}{l}\text { Respon audio bagian } \\
\text { tubuh sapi terdengar } \\
\text { jelas sebanyak } 7 \text { titik }\end{array}$ & $\begin{array}{l}\text { Respon audio bagian } \\
\text { tubuh sapi terdengar } \\
\text { jelas sebanyak } 7 \text { titik }\end{array}$ & 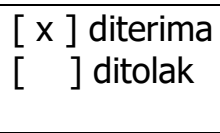 \\
\hline 3 & $\begin{array}{l}\text { Sensor tiap titik yang } \\
\text { disebutkan } \\
\text { keterangan berfungsi } \\
\text { mengeluarkan audio } \\
\text { sesuai bagiannya }\end{array}$ & $\begin{array}{l}\text { Sensor tiap titik yang } \\
\text { disebutkan } \\
\text { keterangan berfungsi } \\
\text { mengeluarkan suara } \\
\text { sesuai bagiannya } \\
\text { sebanyak } 7 \text { titik dan } \\
\text { audio }\end{array}$ & $\begin{array}{l}\text { Sensor tiap titik yang } \\
\text { disebutkan } \\
\text { keterangan } \\
\text { berfungsi } \\
\text { mengeluarkan suara } \\
\text { sesuai bagiannya } \\
\text { sebanyak } 7 \text { titik dan } \\
\text { audio }\end{array}$ & $\begin{array}{l}\text { [x ] diterima } \\
{[\text { ] ditolak }}\end{array}$ \\
\hline
\end{tabular}

Tabel 3. Pengujian Alat Media Pengenalan Bangun Datar

\begin{tabular}{|c|c|c|c|c|}
\hline No & $\begin{array}{l}\text { Aktifitas } \\
\text { Pengujian }\end{array}$ & $\begin{array}{l}\text { Realisasi yang } \\
\text { diharapkan }\end{array}$ & Hasil pengujian & Kesimpulan \\
\hline 1 & $\begin{array}{l}\text { Tekan sensor } \\
\text { bangun datar }\end{array}$ & $\begin{array}{l}\text { Sensor berfungsi } \\
\text { semua yaitu ada } 6 \\
\text { titik }\end{array}$ & $\begin{array}{l}\text { Sensor berfungsi } \\
\text { semua yaitu } \\
\text { sebanyak } 6 \text { titik }\end{array}$ & $\begin{array}{l}\text { [ } \mathrm{x} \text { ] diterima } \\
{[\quad \text { ditolak }}\end{array}$ \\
\hline 2 & $\begin{array}{l}\text { Respon audio } \\
\text { bagian bangung } \\
\text { datar terdengar } \\
\text { saat sensor ditekan }\end{array}$ & $\begin{array}{l}\text { Respon audio bangun } \\
\text { datar terdengar jelas } \\
\text { sebanyak } 6 \text { titik }\end{array}$ & $\begin{array}{l}\text { Respon audio } \\
\text { bangun datar } \\
\text { terdengar jelas } \\
\text { sebanyak } 6 \text { titik }\end{array}$ & 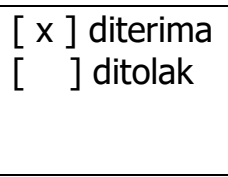 \\
\hline 3 & $\begin{array}{l}\text { Sensor tiap titik } \\
\text { yang disebutkan } \\
\text { keterangan } \\
\text { berfungsi } \\
\text { mengeluarkan } \\
\text { audio sesuai } \\
\text { bagiannya }\end{array}$ & $\begin{array}{l}\text { Sensor tiap titik yang } \\
\text { disebutkan } \\
\text { keterangan berfungsi } \\
\text { mengeluarkan suara } \\
\text { sesuai bagiannya } \\
\text { sebanyak } 6 \text { titik dan } \\
\text { audio }\end{array}$ & $\begin{array}{l}\text { Sensor tiap titik } \\
\text { yang disebutkan } \\
\text { keterangan } \\
\text { berfungsi } \\
\text { mengeluarkan } \\
\text { suara sesuai } \\
\text { bagiannya } \\
\text { sebanyak } 6 \text { titik } \\
\text { dan audio }\end{array}$ & 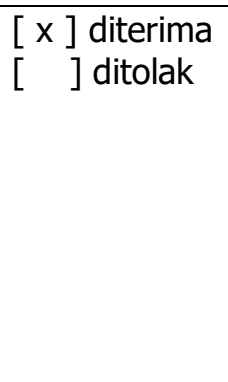 \\
\hline
\end{tabular}

Media pembelajaran yang telah dilakukan uji coba black box, kemudian dilaksanakan kegiatan pelatihan dan penyerahan media pembelajaran. Kegiatan ini dilaksanakan dalam 1 (satu) hari. Gambar 5 menunjukkan kegiatan pemanfaatan media belejaran dan semangat siswa. Siswa diberikan pertanyaan oleh guru materi bangun datar, kemudian siswa menjawab dengan cara menyentuh area sensor yang dianggap sebagai jawaban dari soal yang diberikan oleh guru. Respon media pembelajaran pada area sensor yang mendapat sentuhan mengeluaran audio materi berdasarkan bentuk bangun datar dan warna. Pada kegiatan tanya 
jawab, siswa terlihat antusias dalam menjawab. Bentuk semangat belajar menggunakan media pembelajaran interaktif terlihat dengan adanya siswa mengantri ingin menjawab pertanyaan. Kegiatan penyerahan media pembelajaran interaktif mengenal bagian tubuh sapi dan bangun datar terlihat pada Gambar 6.
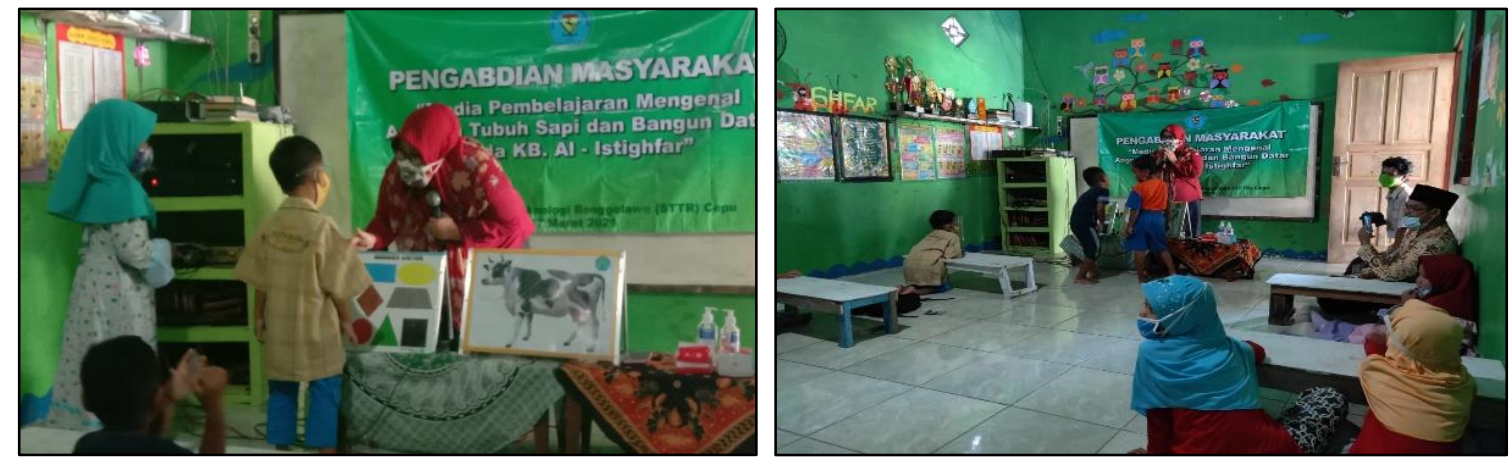

Gambar 5. Antusias Siswa Terhadap Media Pembelajaran Interaktif

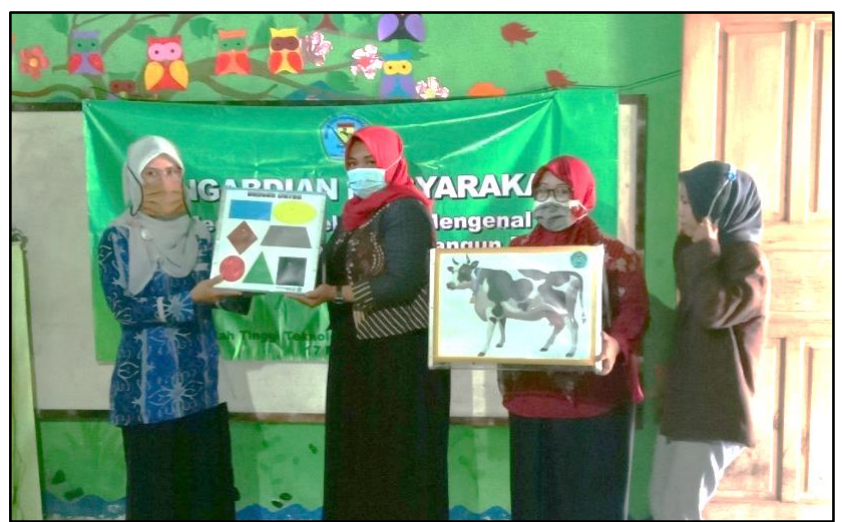

Gambar 6. Kegiatan Penyerahan Media Pembelajaran Interaktif

Sebelum ada media pembelajaran interaktif, guru tidak memiliki media pembelajaran mengenalkan bagian hewan sapi. Sedangkan mengenalkan bangun datar dengan cara menggambar di papan tulis dan hanya mengenalkan bentuk. Setelah memanfaatkan media pembelajaran guru dapat menerangkan bagian sapi dan pengenalan bangun datar tidak hanya dapat mengenal bangun datar tetapi juga mengenal warna. Dengan adanya respon audio menambah semangat siswa dalam belajar. Untuk mengetahui tanggapan guru tentang media pembelajaran dengan memberikan kuesioner yang harus diisi. Hasil pengisian kuesioner dianalisa menggunakan skala likert. Tabel 4 merupakan interval persentase untuk setiap kategori sangat setuju antara $81 \%-100 \%$, setuju $61 \%-80 \%$, tidak setuju $46 \%-60 \%$ dan sangat tidak setuju $\leq 45 \%$.

Tabel 4. Interval Kategori

\begin{tabular}{ll}
\hline Kategori & \%interval \\
\hline Sangat Setuju & $81 \%-100 \%$ \\
Setuju & $61 \%-80 \%$ \\
\hline Tidak Setuju & $46 \%-60 \%$ \\
Sangat Tidak Setuju & $\leq 45 \%$ \\
\hline
\end{tabular}


Persentase hasil pengukuran tanggapan guru terhadap media pembelajaran berdasarkan pengisian kuesioner butir pertanyaan media pembelajaran interaktif mampu memberikan alternatif dalam penyampaian materi sebesar $90 \%$. Hal tersebut sesuai dengan pernyataan Kiromi \& Fauziah (2016) bahwa media pembelajaran dapat memudahkan guru dalam mengajar. Hasil kuesioner butir pertanyaan media pembelajaran memberikan alternatif dalam mengalihkan perhatian anak untuk tidak cepat bosan atau mampu konsentrasi dalam suatu kegiatan dengan waktu yang cukup lama memperoleh persentase $87,5 \%$. Interval nilai masuk kategori sangat setuju, berarti media pembelajaran mampu mengalihkan perhatian anak agar tidak cepat bosan (Yanti et al., 2019). Media pembelajaran dengan respon audio meningkatkan minat belajar siswa sebesar $87,5 \%$. Sejalan dengan pernyataan Gabriela (2021) bahwa pemanfaatan media pembelajaran berbasis audio menunjukkan peningkatkan minat belajar siswa. Butir pertanyaan mudah pengaplikasian $90 \%$ dan media pembelajaran bekerja dengan baik memperoleh nilai $85 \%$. Hal tersebut meunjukan bahwa penggunaan kapasitif sensor mudah penggunaannya dan mampu mengirimkan data dengan benar (Yuniaratri et al., 2017; Wahyusari, 2018; Hanggara et al., 2021). Hasil keseluruhan nilai kuesioner mendapat rata-rata sebesar $88 \%$, masuk kedalam kategori sangat setuju.

Tabel 5 Hasil Kuesioner Pengabdian Media Pembelajaran Interaktif

\begin{tabular}{lcc}
\hline \multicolumn{1}{c}{ Butir Pertanyaan } & $\begin{array}{c}\text { Persetase } \\
(\mathbf{\%})\end{array}$ & Keterangan \\
\hline $\begin{array}{l}\text { Media pembelajaran membantu saya dalam menyampaikan } \\
\text { materi }\end{array}$ & 90 & Sangat Setuju \\
$\begin{array}{l}\text { Media pembelajaran memberikan alternatif dalam mengalihkan } \\
\text { perhatian anak untuk tidak cepat bosan atau mampu } \\
\text { konsentrasi dalam suatu kegiatan dengan waktu yang cukup } \\
\text { lama }\end{array}$ & 87,5 & Sangat Setuju \\
$\begin{array}{l}\text { Media pembelajaran dengan respon audio meningkatkan minat } \\
\text { belajar siswa }\end{array}$ & 87,5 & Sangat Setuju \\
$\begin{array}{l}\text { Media pembelajaran mudah pengaplikasiannya } \\
\text { Rata-Rata }\end{array}$ & 90 & Sangat Setuju \\
$\begin{array}{l}\text { Media pembelajaran bekerja dengan baik } \\
\quad 85\end{array}$ & Sangat Setuju \\
\hline
\end{tabular}

\section{Kesimpulan}

Materi media pembelajaran interaktif mengenal anggota tubuh sapi dan bangun datar sesuai dengan harapan guru, serta berdasarkan hasil uji black box yang dilaksanakan oleh tim dan guru mendapatkan hasil media pembelajaran dapat bekerja dengan baik. Media pembelajaran meningkatkan semangat siswa dalam belajar, terlihat dari banyaknya siswa yang ingin berinteraksi dengan media pembelajaran. Sedangkan hasil pengukuran tanggapan guru terhadap media pembelajaran mendapat rata-rata $88 \%$, nilai masuk pada interval sangat setuju. Maka dapat dikatakan pengembangan media pembelajaran interaktif memberikan alternatif 
guru dalam menyampaikan materi, penambahan respon audio mampu meningkatkan minat belajar siswa serta mampu mengalihkan perhatian anak sehinnga tidak cepat mengalami kebosanan dalam pembelajaran.

\section{Ucapan Terima Kasih}

Tim pelaksanaan kegiatan pengabdian pemanfaatan media pembelajaran interaktif mengucapkan terima kasih atas dukungan dan kerjasama Pusat Penelitian dan Pengabdian Kepada Masyarakat (UPT. P3M) STTR Cepu, petugas workshop Teknik Elektro, mahasiswa, serta peran aktif mitra KB. Al-Istighfar Desa Tambakwatu, Karangboyo, Kecamatan Cepu, Kabupaten Blora.

\section{Referensi}

Anam, N. (2021). Berbagai Problematika Pendidikan Dan Pembelajaran Di Dalam Lembaga Pendidikan PAUD Dan TK/RA Di Indonesia. Https://Iaiq.Ac.Id.

Ayuni, S. N. (2019). Pengelolaan Media Pembelajaran Anak Usia Dini di TK PGRI Tolot-Tolot Kec. Pujut Tahun Pelajaran 2017/1018. Jurnal IImu Sosail Dan Pendidikan, 3(2), 22-32. http://dx.doi.org/10.36312/jisip.v3i2.715

Bagye, W., Azizah, T., \& Zulkarnaen, M. F. (2018). Alat Pengaman Kandang Berbasis Mikrokontroler Arduino Uno. Jurnal Informatika Dan Rekayasa Elektronik, 1(2), 62. https://doi.org/10.36595/jire.v1i2.61

Dwansi, R. M., Riswandi, \& Surahman, M. (2017). Pengenalan Geometri Anak Usia Dini Melalui Media Manipulatif. Jurnal Pendidikan Anak, 3(1).

Febiola, K. A. (2020). Peningkatan Kemampuan Berhitung Permulaan Anak Usia Dini Melalui Pengembangan Media Pembelajaran Pohon Angka. Jurnal Ilmiah Pendidikan Profesi Guru, 3(2), 238. https://doi.org/10.23887/jippg.v3i2.28263

Gabriela, N. D. P. (2021). Pengaruh Media Pembelajaran Berbasis Audio Visual Terhadap Peningkatan Hasil Belajar Siswa Sekolah Dasar. Pendidikan Guru Sekolah Dasar, 2(1), 104-113. https://ummaspul.e-journal.id/MGR/article/download/1750/574

Hanggara, D., Dani, R., \& Putra, E. (2021). Purwarupa Perangkat Deteksi Dini Banjir Berbasis Internet of Things. JIRE (Jurnal Informatika \& Rekayasa Elektronika), 4(1), 87-94. https://doi.org/10.36595/jire.v4i1.349

Jufriyanto, J., Zulkarnain, M., Irvawansyah, \& Mustafa, S. (2020). Rancang Bangun Media Pembelajaran Penyortiran Benda Berbasis Mikrokontroler. Journal of Electrical Engineering, 1(1), 32-40. https://doi.org/10.1234/joule.v1i1.52

Kiromi, I. H., \& Fauziah, P.Y. (2016). Pengembangan Media Pembelajaran Big Book Untuk Membantu Karaker Anak Usia Dini. Jurnal Pendidikan Dan Pemberdayaan Masyarakat, 3(1), 48-59. https://doi.org/10.21831/jppm.v3i1.5594

Lesmana, C., Hartono, H., Permana, R., \& Matsun, M. (2018). Pelatihan dan Pendampingan Pembuatan Media Pembelajaran Berbasis Multimedia Interaktif Untuk Guru Smp Negeri 1 Sungai Kakap. Jurnal Transformasi, 14(2), 139-147. https://doi.org/10.20414/transformasi.v14i2.587

Mardhiah, A., \& Ali Akbar, S. (2018). Efektivitas Media Pembelajaran Terhadap Hasil Belajar Kimia Siswa Sma Negeri 16 Banda Aceh. Lantanida Journal, 6(1), 49. https://doi.org/10.22373/lj.v6i1.3173

Nurrita, T. (2018). Pengembangan Media Pembelajaran Untuk Meningkatkan Hasil Belajar Siswa. MISYKAT: Jurnal IImu-IImu Al-Quran, Hadist, Syariah Dan Tarbiyah, 3(1), 171. https://doi.org/10.33511/misykat.v3n1.171

Nusyirwan, D., \& Purnama, M. B. (2019). TEPIKAN (Tebak Pilihan Ikan) Menggunakan Card Tag RFID Berbasis Arduino Uno Sebagai Media Belajar Anak Sekolah. Simetris : Jurnal Teknik Mesin, Elektro Dan I/mu Komputer, 10(2), 589-602.

Shalikhah, N. D. (2017). Media Pembelajaran Interaktif Lectora Inspire sebagai Inovasi 
Pembelajaran. Warta LPM, 20(1), 9-16. https://doi.org/10.23917/warta.v19i3.2842

Tafonao, T. (2018). Peranan Media Pembelajaran Dalam Meningkatkan Minat Belajar Mahasiswa. Jurnal Komunikasi Pendidikan, 2(2), 103-114. https://doi.org/10.32585/jkp.v2i2.113

Tatik Ariyanti. (2016). Pentingnya Pendidikan Anak Usia Dini Bagi Tumbuh Kembang Anak The Importance Of Childhood Education For Child Development. Jurnal Dinamika Pendidikan Dasar, $8(1)$.

Wahyusari, R., Wibowo, L., \& Amrozi, M. A. (2018). Rancang Bangun Saron Digital (Laron) Berbasis Capacitive Sensor Pada Arduino Uno. Simetris: Jurnal Teknik Mesin, Elektro Dan Ilmu Komputer, 12(1), 32-34.

Wicaksono, M. F., \& Qhadafhi, M. (2019). Pengembangan Alat Pengenalan Bentuk Bangun Geometri Untuk Anak Usia Dini Berbasis Mikrokontroler. CCIT Journal, 12(2), 186-196. https://doi.org/10.33050/ccit.v12i2.689

Yanti, C. O. D., Anggraini, F., \& Darwanto. (2019). Media Pembelajaran Matematika Interaktif Dalam Upaya Menumbuhkan Karakter Siswa. Semnasfip, 201-206. https://jurnal.umj.ac.id/index.php/SEMNASFIP/article/view/5128

Yuniaratri, R., Suryanto, A., \& Mulwinda, A. (2017). Implementasi Capacitive Sensor pada Arduino dalam Perancangan Bonang Elektronik. Edu Komputika Journal, 4(1), 39-39. https://doi.org/10.15294/edukomputika 